\title{
Desempenho de frangos caipiras alimentados com farelo integral de mandioca
}

\author{
Performance of broilers redneack fed cassava meal
}

\section{HOLANDA, Marco Aurélio Carneiro de ${ }^{1}$; HOLANDA, Mônica Calixto Ribeiro de ${ }^{1 *}$; VIGODERES, Ricardo Brauer²; DUTRA JUNIOR, Wilson Moreira ${ }^{3}$; ALBINO, Luiz Fernando Teixeira $^{4}$}

\author{
${ }^{1}$ Universidade Federal Rural de Pernambuco, Serra Talhada, Pernambuco, Brasil. \\ ${ }^{2}$ Universidade Federal Rural de Pernambuco, Garanhuns, Pernambuco, Brasil. \\ ${ }^{3}$ Universidade Federal Rural de Pernambuco, Departamento de Zootecnia, Recife, Pernambuco, Brasil. \\ ${ }^{4}$ Universidade Federal de Viçosa, Departamento de Zootecnia, Viçosa, Minas Gerais, Brasil. \\ *Endereço para correspondência: mcarneirodeholanda@gmail.com
}

\section{RESUMO}

Objetivou-se avaliar o desempenho produtivo e características de carcaça de frangos caipiras alimentados com dietas contendo farelo integral de mandioca em níveis crescentes de inclusão de 12, 24, 36 e 48\%. Foram utilizados 360 pintos, machos da linhagem Label Rouge, com oito dias de idade, distribuídos em delineamento inteiramente casualizado com cinco tratamentos e seis repetições, contendo 12 aves por parcela. As aves foram alimentadas com dietas isoproteicas e isocalóricas dos oito aos 84 dias. Os parâmetros avaliados foram consumo de ração, ganho de peso, conversão alimentar. Foram abatidas duas aves por parcela com desvio padrão de $\pm 5 \%$ do peso médio da parcela para avaliação do rendimento de carcaça e de cortes comerciais, asa, peito, coxa, sobrecoxa, dorso, gordura abdominal e vísceras comestíveis (fígado, coração e moela). Os dados foram submetidos a analises de variância e regressão ao nível de $5 \%$ de probabilidade com uso do programa computacional SAS (2001). Conclui-se que houve aumento linear no ganho de peso das aves e no consumo de ração com o aumento dos níveis de inclusão do farelo integral de mandioca, podendo ser utilizado em até $48 \%$ na ração sem prejuízo do desempenho zootécnico.

Palavras-chave: alimento alternativo, aves caipiras, ganho de peso, conversão alimentar

\section{SUMMARY}

This study aimed to evaluate the performance and carcass characteristics of rednecks chickens fed diets containing the cassava root meal in increasing levels of inclusion of 12, 24, 36 and 48\%. 360 chicks male, lineage Label Rouge were used, with eight days old, in a completely randomized design with five treatments and six replications of 12 birds each. The birds were fed isocaloric and isonitrogenous from eight to 84 days. Was evaluated feed intake, weight gain and feed conversion. Were killed two birds per cage with $5 \% \pm$ standard deviation of the mean weight of the cage for evaluation of carcass yield and retail cuts, wings, breast, drumstick, thigh, back, abdominal fat and edible offal (liver, heart and gizzard). Data were subjected to analysis of variance and regression at $5 \%$ probability using the computer program SAS (2001). Concluded that there was a linear increase in weight gain of birds and feed intake with increasing levels of inclusion of the cassava root meal, can be used up to $48 \%$ in the diet without prejudice to animal performance.

Keywords: alternative food, free range birds, weight gain, fed conversion 
Rev. Bras. Saúde Prod. Anim., Salvador, v.16, n.1, p.106-117 jan./mar., 2015 http://www.rbspa.ufba.br

\section{INTRODUÇÃO}

A produção de frangos caipiras tem se constituído como importante ferramenta de trabalho para agricultores participantes da agricultura familiar e têm se mostrado ao longo do tempo como nicho de mercado por ser uma atividade lucrativa, sustentável, e a carne da ave ser de ótima qualidade nutricional e saborosa. No entanto o uso de ingredientes tradicionais utilizados na avicultura industrial como milho e farelo de soja em algumas épocas do ano tem seus preços bastante elevados encarecendo o custo de produção dessas aves, pois o pequeno produtor não consegue manter estoques suficientemente elevados de grãos capaz de suprir a demanda durante todo o ano.

A mandioca e seus subprodutos são identificados como alternativas viáveis para inclusão nas rações das aves por serem alimentos comuns em países tropicais e subtropicais (LUDKE et al., 2005), além de baixo custo e de grande disponibilidade, porém contém fatores antinutricionais que são os glicosídeos cianogênicos de dois tipos, linamarina que representa $93 \%$ do total e a linamarina etílica, com 7\%, chamada de lotaustralina (CHAUYNARONG et al., 2009).

Ludke et al. (2005) relataram que a mandioca é uma boa fonte de energia, devido ao alto nível de carboidratos (amido), propriedades aglutinantes $\mathrm{e}$ elevado coeficiente de digestibilidade, sendo porém, pobre em proteína bruta, aminoácidos sulfurados, gordura, ácidos graxos essenciais, vitaminas, minerais e pigmentantes naturais.

Freitas et al. (2008) avaliando a farinha de varredura de mandioca em rações de frangos de corte obtiveram valores de energia metabolizável aparente (EMA) de $2.940 \mathrm{kcal} / \mathrm{kg}$, e observaram a viabilidade do uso em até $30 \%$ de farinha de raspa de mandioca em substituição ao milho nas rações de engorda dos frangos de corte sem afetar o desempenho das aves.

Carrijo et al. (2010) avaliando o uso de farelo de raízes de mandioca para aves caipiras observaram que o farelo de raízes de mandioca pode ser utilizado até o nível de $45 \%$ sem causar prejuízo ao desempenho das aves.

Apesar dos resultados promissores apresentados na literatura, a utilização da mandioca e seus coprodutos ainda é realizada com cautela em rações para aves por causa dos fatores antinutricionais encontrados na planta, da dificuldade do beneficiamento para retirada do excesso de umidade entre outros. Diante do exposto objetivou-se avaliar o desempenho zootécnico de frangos de corte caipiras, alimentados com farelo integral de mandioca.

\section{MATERIAL E MÉTODOS}

A pesquisa foi aprovada e conduzida de acordo com as normas do Comitê de Ética no Uso de Animais da Universidade Federal Rural de Pernambuco (CEUA-UFRPE), no setor de Avicultura do Departamento de Zootecnia (DZ) da UFRPE, localizado na cidade do Recife, PE.

Foram alojadas 360 aves da linhagem Label Rouge, machos, com um dia de idade, com peso inicial de aproximadamente $40 \mathrm{~g}$, criados até os sete dias de idade de acordo com as recomendações do manual da linhagem. Foram vacinados no incubatório contra as doenças de Mareck, Gumboro e Newcastle, sendo revacinados aos 21 dias de idade, via água de bebida, e vacinados contra Bouba aviária por punção da membrana da asa.

Aos oito dias de idade as aves foram 
Rev. Bras. Saúde Prod. Anim., Salvador, v.16, n.1, p.106-117 jan./mar., 2015 http://www.rbspa.ufba.br ISSN 15199940

distribuídas em um delineamento inteiramente casualisado com cinco tratamentos e seis repetições com 12 aves por parcela, totalizando 360 aves em 30 unidades experimentais. As aves foram pesadas individualmente aos sete dias de idade e distribuídas nas parcelas para máxima uniformidade considerando um desvio padrão de $\pm 10 \%$ do peso médio.

A temperatura do ambiente foi controlada de acordo com o comportamento dos pintos sob a fonte de calor e tanto temperatura quanto a umidade relativa do ar foram monitoradas e anotadas diariamente às $9 \mathrm{~h} 00 \mathrm{~min}$ e às $16 \mathrm{~h} 00 \mathrm{~min}$ utilizando-se um termo-higrômetro digital.

Por todo o período experimental (84 dias) a iluminação foi de 24 horas diárias (natural + artificial) e as aves foram mantidas confinadas sem acesso a piquetes, com manejo semelhante ao empregado na criação de frangos industriais.

O farelo integral de mandioca foi obtido através da moagem da raiz integral de mandioca em moinho tipo "rodete", específico para fabricação de farinhas de mesa, com posterior secagem ao sol por cinco dias, até atingir $14 \%$ de umidade no material determinada por um analisador de umidade para matérias primas.

Para a formulação das dietas, o farelo integral de mandioca utilizado foi analisado no Laboratório de Nutrição Animal do DZ-UFRPE, segundo a metodologia descrita pela Association and Analitical Chemist (AOAC, 1995). A energia bruta do ingrediente foi determinada em calorímetro adiabático do Departamento de Zootecnia da UFRPE, a energia metabolizável aparente foi determinada em um experimento de metabolismo realizado previamente (Tabela 1).
Tabela 1. Composição nutricional do farelo integral de mandioca (Manihot esculenta Crantz) analisado e utilizado nas dietas experimentais.

\begin{tabular}{lc}
\hline Composição & Valores \\
\hline Matéria seca (\%) & 80,53 \\
Matéria orgânica (\%) & 87,28 \\
Proteína bruta (\%) & 2,14 \\
Extrato etéreo (\%) & 0,25 \\
Fibra bruta (\%) & 3,32 \\
Fibra em detergente neutro (\%) & 6,89 \\
Fibra em detergente ácido (\%) & 4,15 \\
Cinzas (\%) & 1,65 \\
\hline Energia bruta, (Kcal/kg) & 3.640 \\
\hline Energia metabolizável, (Kcal/kg) & 2.951 \\
\hline
\end{tabular}

Foram formuladas cinco dietas experimentais, isoproteicas e isoenergéticas segundo as recomendações de Nascimento et al. (2009 a, b) para aminoácidos e de Mendonça et al. (2007) para energia metabolizável. Os tratamentos constaram de uma dieta referência à base de milho e farelo de soja e de quatro dietas teste com níveis de inclusão de 12, 24, 36 e $48 \%$ de farelo integral de mandioca (FIM).

As rações experimentais foram peletizadas artesanalmente, sendo a massa umidificada com água aquecida a uma temperatura de $65^{\circ} \mathrm{C}$, adicionada no percentual de $10 \%$ da massa. Para formação dos péletes utilizou-se um triturador industrial de carnes acionado com motor elétrico de 2 HP.

O programa de alimentação durante a fase pré-inicial, foi realizado com uma dieta a base de milho e farelo de soja, porém, o experimento só teve início aos oito dias de idade das aves, quando as parcelas foram homogeneizadas por peso e se iniciou o fornecimento das dietas experimentais.

O programa de alimentação adotado contemplou quatro fases: de um a sete dias (pré-incial) com 19,3\% proteína bruta (PB) e $2.750 \mathrm{Kcal} / \mathrm{kg}$; dos oito aos 
Rev. Bras. Saúde Prod. Anim., Salvador, v.16, n.1, p.106-117 jan./mar., 2015 http://www.rbspa.ufba.br ISSN 15199940

28 dias (inicial) com 19,3\% PB e $2.750 \mathrm{Kcal} / \mathrm{kg} ;$ dos 29 aos 56 dias (crescimento) com $19,5 \%$ PB e $2.850 \mathrm{Kcal} / \mathrm{kg}$; e dos 57 aos 84 dias (final) com $18,0 \%$ PB e $3.100 \mathrm{Kcal} / \mathrm{kg}$ (Tabelas 2, 3 e 4).

As aves receberam água e ração à vontade. Realizou-se a pesagem das aves e das sobras de ração de cada parcela experimental a cada sete dias e os registros de mortalidade quando ocorrido, foram anotados, para correção dos valores do ganho de peso, consumo de ração e conversão alimentar.

Ao final do experimento duas aves por parcela representando o peso médio da mesma, foram insensibilizadas $\mathrm{e}$ eutanasiadas para avaliação do rendimento de carcaça, de suas partes (asas, dorso, peito, coxa, sobrecoxa), gordura abdominal e das vísceras comestíveis (fígado, coração e moela).

Tabela 2. Composição centesimal, química e energética das dietas ofertadas às aves no período de oito a 28 dias de idade, na matéria natural.

\begin{tabular}{|c|c|c|c|c|c|}
\hline \multirow[t]{2}{*}{ Ingredientes } & \multicolumn{5}{|c|}{$\begin{array}{l}\text { Níveis de inclusão do farelo integral de mandioca } \\
\text { (Manihot esculenta Crantz), }(\%)\end{array}$} \\
\hline & 0 & 12 & 24 & 36 & 48 \\
\hline Milho moído (\%) & 55,050 & 41,280 & 27,520 & 13,760 & 0,000 \\
\hline Farelo de soja (\%) & 25,600 & 27,600 & 29,600 & 31,600 & 33,600 \\
\hline Farelo integral de mandioca $(\%)$ & 0,000 & 12,000 & 24,000 & 36,000 & 48,000 \\
\hline Farelo de trigo $(\%)$ & 14,752 & 14,560 & 14,364 & 14,164 & 13,965 \\
\hline Calcário calcítico (\%) & 1,820 & 1,760 & 1,695 & 1,632 & 1,570 \\
\hline Fosfato bicálcico (\%) & 1,400 & 1,425 & 1,450 & 1,475 & 1,500 \\
\hline Cloreto de sódio (\%) & 0,460 & 0,450 & 0,440 & 0,430 & 0,420 \\
\hline L-Lisina $(\%)$ & 0,364 & 0,340 & 0,315 & 0,292 & 0,267 \\
\hline DL-Metionina (\%) & 0,254 & 0,285 & 0,316 & 0,347 & 0,378 \\
\hline Premix Vitaminíco1 (\%) & 0,100 & 0,100 & 0,100 & 0,100 & 0,100 \\
\hline Premix Mineral2 (\%) & 0,100 & 0,100 & 0,100 & 0,100 & 0,100 \\
\hline Cloreto de Colina (\%) & 0,100 & 0,100 & 0,100 & 0,100 & 0,100 \\
\hline Total & 100,00 & 100,00 & 100,00 & 100,00 & 100,00 \\
\hline \multicolumn{6}{|l|}{ Composição química } \\
\hline Energia metabolizável (Mcal/kg) & 2,750 & 2,750 & 2,750 & 2,750 & 2,750 \\
\hline Proteína bruta (\%) & 19,300 & 19,300 & 19,300 & 19,300 & 19,300 \\
\hline Proteína bruta analisada (\%) & 19,600 & 19,800 & 19,600 & 19,200 & 19,800 \\
\hline Amido (\%) & 37,750 & 37,980 & 38,250 & 38,460 & 38,700 \\
\hline Cálcio (\%) & 1,160 & 1,160 & 1,160 & 1,160 & 1,160 \\
\hline Fósforo disponível (\%) & 0,394 & 0,394 & 0,394 & 0,394 & 0,394 \\
\hline Cloro $(\%)$ & 0,302 & 0,298 & 0,293 & 0,289 & 0,285 \\
\hline Fibra bruta $(\%)$ & 3,900 & 4,090 & 4,280 & 4,470 & 4,660 \\
\hline Lisina digestível (\%) & 1,041 & 1,041 & 1,041 & 1,041 & 1,041 \\
\hline Metionina+Cistina digestível (\%) & 0,740 & 0,740 & 0,740 & 0,740 & 0,740 \\
\hline Metionina digestível (\%) & 0,512 & 0,517 & 0,527 & 0,548 & 0,568 \\
\hline Potássio (\%) & 0,748 & 0,784 & 0,820 & 0,857 & 0,893 \\
\hline Sódio (\%) & 0,221 & 0,221 & 0,221 & 0,221 & 0,221 \\
\hline
\end{tabular}

${ }^{\top}$ Premix Vitamínico (composição/kg de produto): Ácido Fólico 106,00 mg; Pantotênico $2.490 \mathrm{mg}$; Antifúngico $5.000 \mathrm{mg}$; Antioxidante $200 \mathrm{mg}$; Biotina $21 \mathrm{mg}$; Coccidiostático $15.000 \mathrm{mg}$; Colina 118.750 $\mathrm{mg}$; Vitamina K3 525,20 mg; Niacina $7.840 \mathrm{mg}$; Piridoxina $210 \mathrm{mg}$; Riboflavina $1.660 \mathrm{mg}$, Tiamina 360 mg; Vitamina A 2.090.000 UI; Vitamina B12 123.750 mcg; Vitamina D3 525.000UI; Vitamina E 4.175 mg. 2 Premix Mineral (composição/ kg de produto): Cu 2.000mg; I 190 mg; Mn 18.750 mg; Se 75 $\mathrm{mg}$; Zn $12.500 \mathrm{mg}$. 
Tabela 3. Composição centesimal, química e energética das dietas ofertadas às aves no período de 29 a 56 dias de idade, na matéria natural.

\begin{tabular}{|c|c|c|c|c|c|}
\hline \multirow{2}{*}{ Ingredientes } & \multicolumn{5}{|c|}{ Níveis de inclusão do farelo integral de mandioca (Manihot esculenta Crantz), (\%) } \\
\hline & 0 & 12 & 24 & 36 & 48 \\
\hline Milho moído (\%) & 59,630 & 44,730 & 29,783 & 14,870 & 0,000 \\
\hline Farelo de soja (\%) & 27,300 & 28,650 & 30,050 & 31,420 & 32,860 \\
\hline Farelo integral de mandioca $(\%)$ & 0,000 & 12,000 & 24,000 & 36,000 & 48,000 \\
\hline Farelo de trigo $(\%)$ & 9,760 & 10,960 & 12,160 & 13,360 & 14,443 \\
\hline Calcário calcítico (\%) & 0,942 & 0,896 & 0,844 & 0,792 & 0,740 \\
\hline Óleo de soja (\%) & 0,000 & 0,368 & 0,735 & 1,100 & 1,470 \\
\hline Fosfato bicálcico $(\%)$ & 1,210 & 1,220 & 1,230 & 1,240 & 1,250 \\
\hline Cloreto de sódio (\%) & 0,410 & 0,403 & 0,395 & 0,388 & 0,380 \\
\hline L-Lisina $(\%)$ & 0,251 & 0,240 & 0,228 & 0,217 & 0,205 \\
\hline DL-Metionina (\%) & 0,197 & 0,236 & 0,275 & 0,313 & 0,352 \\
\hline Premix Vitaminíco1 (\%) & 0,100 & 0,100 & 0,100 & 0,100 & 0,100 \\
\hline Premix Mineral2 (\%) & 0,100 & 0,100 & 0,100 & 0,100 & 0,100 \\
\hline Cloreto de Colina (\%) & 0,100 & 0,100 & 0,100 & 0,100 & 0,100 \\
\hline \multirow[t]{2}{*}{ Total } & 100,00 & 100,00 & 100,00 & 100,00 & 100,00 \\
\hline & \multicolumn{5}{|c|}{ Composição química } \\
\hline Energia metabolizável (Mcal/kg) & 2,850 & 2,850 & 2,850 & 2,850 & 2,850 \\
\hline Proteína bruta $(\%)$ & 19,500 & 19,500 & 19,500 & 19,500 & 19,500 \\
\hline Proteína bruta analisada (\%) & 20,200 & 20,000 & 20,400 & 20,800 & 20,000 \\
\hline Amido (\%) & 40,830 & 40,150 & 39,470 & 38,790 & 38,110 \\
\hline Cálcio (\%) & 0,780 & 0,780 & 0,780 & 0,780 & 0,780 \\
\hline Fósforo disponível (\%) & 0,351 & 0,351 & 0,351 & 0,351 & 0,351 \\
\hline Cloro $(\%)$ & 0,277 & 0,272 & 0,267 & 0,262 & 0,257 \\
\hline Fibra bruta $(\%)$ & 3,650 & 3,912 & 4,175 & 4,437 & 4,700 \\
\hline Lisina digestível (\%) & 1,006 & 1,006 & 1,006 & 1,006 & 1,006 \\
\hline Metionina+Cistina digestível (\%) & 0,716 & 0,716 & 0,716 & 0,716 & 0,716 \\
\hline Metionina digestível (\%) & 0,448 & 0,472 & 0,497 & 0,521 & 0,546 \\
\hline Potássio $(\%)$ & 0,755 & 0,792 & 0,828 & 0,865 & 0,902 \\
\hline Sódio $(\%)$ & 0,203 & 0,203 & 0,203 & 0,203 & 0,203 \\
\hline
\end{tabular}

1 Premix Vitamínico (composição/ kg de produto): Ácido Fólico 106,00 mg; Pantotênico 2.490 mg; Antifúngico 5.000 mg; Antioxidante 200 mg; Biotina 21 mg; Coccidiostático $15.000 \mathrm{mg}$; Colina $118.750 \mathrm{mg}$; Vitamina K3 525,20 mg; Niacina 7.840 mg; Piridoxina 210 mg; Riboflavina 1.660 mg, Tiamina 360 mg; Vitamina A 2.090.000 UI; Vitamina B12 123.750 mcg; Vitamina D3 525.000UI; Vitamina E 4.175 mg. 2 Premix Mineral (composição/ kg de produto): Cu 2.000 mg; I 190 mg; Mn 18.750 mg; Se 75 mg; Zn 12.500 mg 
Tabela 4. Composição centesimal, química e energética das dietas ofertadas às aves no período de 57 a 84 dias de idade na matéria natural.

\begin{tabular}{|c|c|c|c|c|c|}
\hline \multirow{2}{*}{ Ingredientes } & \multicolumn{5}{|c|}{ Níveis de inclusão do farelo integral de mandioca (Manihot esculenta Crantz), (\%) } \\
\hline & 0 & 12 & 24 & 36 & 48 \\
\hline Milho moído (\%) & 70,574 & 56,742 & 42,915 & 29,088 & 15,256 \\
\hline Farelo de soja $(\%)$ & 25,360 & 27,185 & 29,010 & 30,835 & 32,660 \\
\hline Farelo integral de mandioca $(\%)$ & 0,000 & 12,000 & 24,000 & 36,000 & 48,000 \\
\hline Óleo de soja $(\%)$ & 0,990 & 1,060 & 1,125 & 1,192 & 1,260 \\
\hline Calcário calcítico (\%) & 0,750 & 0,691 & 0,632 & 0,574 & 0,515 \\
\hline Fosfato bicálcico (\%) & 1,200 & 1,220 & 1,240 & 1,257 & 1,277 \\
\hline Cloreto de sódio (\%) & 0,332 & 0,321 & 0,311 & 0,300 & 0,290 \\
\hline L-Lisina $\mathrm{HCl}(\%)$ & 0,342 & 0,319 & 0,295 & 0,272 & 0,250 \\
\hline DL-Metionina (\%) & 0,152 & 0,162 & 0,172 & 0,182 & 0,192 \\
\hline Premix Vitaminíco1 (\%) & 0,100 & 0,100 & 0,100 & 0,100 & 0,100 \\
\hline Premix Mineral2 (\%) & 0,100 & 0,100 & 0,100 & 0,100 & 0,100 \\
\hline Cloreto de Colina (\%) & 0,100 & 0,100 & 0,100 & 0,100 & 0,100 \\
\hline \multirow[t]{2}{*}{ Total } & 100,00 & 100,00 & 100,00 & 100,00 & 100,00 \\
\hline & \multicolumn{5}{|c|}{ Composição química } \\
\hline Energia metabolizável (Mcal/kg) & 3,100 & 3,100 & 3,100 & 3,100 & 3,100 \\
\hline Proteína bruta $(\%)$ & 18,000 & 18,000 & 18,000 & 18,000 & 18,000 \\
\hline Proteína bruta analisada (\%) & 18,800 & 18,100 & 18,600 & 18,200 & 18,600 \\
\hline Amido (\%) & 47,420 & 47,437 & 47,455 & 47,472 & 47,490 \\
\hline Cálcio (\%) & 0,686 & 0,737 & 0,788 & 0,839 & 0,890 \\
\hline Fósforo disponível (\%) & 0,325 & 0,325 & 0,325 & 0,325 & 0,325 \\
\hline Cloro $(\%)$ & 0,236 & 0,248 & 0,260 & 0,272 & 0,285 \\
\hline Fibra bruta $(\%)$ & 2,880 & 3,125 & 3,370 & 3,615 & 3,860 \\
\hline Lisina digestível (\%) & 0,760 & 0,760 & 0,760 & 0,760 & 0,760 \\
\hline Metionina+Cistina digestível (\%) & 0,756 & 0,756 & 0,756 & 0,756 & 0,756 \\
\hline Metionina digestível (\%) & 0,410 & 0,410 & 0,410 & 0,410 & 0,410 \\
\hline Potássio $(\%)$ & 0,678 & 0,724 & 0,770 & 0,816 & 0,862 \\
\hline Sódio (\%) & 0,170 & 0,170 & 0,170 & 0,170 & 0,170 \\
\hline
\end{tabular}

1 Premix Vitamínico (composição/ kg de produto): Ácido Fólico 106,00 mg; Pantotênico $2.490 \mathrm{mg}$; Antifúngico 5.000 mg; Antioxidante 200 mg; Biotina $21 \mathrm{mg}$; Coccidiostático 15.000 mg; Colina 118.750 mg; Vitamina K3 525,20 mg; Niacina 7.840 mg; Piridoxina 210 mg; Riboflavina 1.660 mg, Tiamina 360 mg; Vitamina A 2.090.000 UI; Vitamina B12 123.750 mcg; Vitamina D3 525.000UI; Vitamina E 4.175 mg. 2 Premix Mineral (composição/ kg de produto): Cu 2.000 mg; I 190 mg; Mn $18.750 \mathrm{mg}$; Se $75 \mathrm{mg}$; Zn $12.500 \mathrm{mg}$ 
Rev. Bras. Saúde Prod. Anim., Salvador, v.16, n.1, p.106-117 jan./mar., 2015 http://www.rbspa.ufba.br ISSN 15199940

As aves foram selecionadas de acordo com peso médio da parcela com $\mathrm{o}$ desvio padrão de $\pm 5 \%$ e submetidas a jejum alimentar por quatro horas. Em seguida foram pesadas individualmente, abatidas, sangradas na jugular, depenadas, evisceradas, novamente pesadas para obtenção do peso da carcaça (sem os pés, cabeça e gordura total) e armazenadas em freezer a $-12^{\circ} \mathrm{C}$. Em seguida, foram pesadas as vísceras comestíveis (fígado, coração e moela) e a gordura abdominal. No dia seguinte foram efetuados os cortes nobres (peito, coxa, sobrecoxa, asa e dorso) e mensurados os respectivos pesos.

Os resultados foram submetidos à análise de variância e ao teste de regressão, utilizando-se o programa computacional SAS (STATISTICAL ANALYSIS SYSTEMS, 2001) e para análise da significância foi utilizado o teste de Fisher a $5 \%$ de probabilidade, seguindose o modelo $\hat{Y} i j=\mu+T i+\varepsilon i j$, em que:

$\hat{Y} \mathrm{ij}=$ parâmetros avaliados em cada unidade experimental $\mathrm{j}$ recebendo $\mathrm{o}$ tratamento $\mathrm{i}$;

$\mu=$ média estimada;

Ti = efeito do nível de inclusão do farelo integral de raízes de mandioca, sendo $\mathrm{i}=1,2, \ldots, 5$ os níveis de inclusão $0,12, \ldots, 48 \%$;

$\mathbf{J}=1,2, \ldots 6$ repetições dentro de cada nível de inclusão do farelo; e

$\varepsilon \mathrm{ij}=$ erro aleatório associado a cada observação.

\section{RESULTADOS E DISCUSSÃO}

As temperaturas médias do ambiente observadas durante $\mathrm{o}$ período experimental foram de 23 e $34^{\circ} \mathrm{C}$, para mínima e máxima, respectivamente, com umidade relativa do ar oscilando entre $63 \%$ e $76 \%$.

As médias de peso vivo, de ganho de peso, consumo de ração e de conversão alimentar das aves, por fase de produção, são apresentadas na Tabela 5.

Tabela 5. Médias de ganho de peso (GP), consumo de ração (CR) e conversão alimentar (CA), observadas em função da inclusão de farelo integral de mandioca (FIM)

\begin{tabular}{|c|c|c|c|c|c|c|c|c|}
\hline \multirow[t]{2}{*}{ Variável } & \multirow{2}{*}{$\begin{array}{l}\text { Fase } \\
\text { (dias) }\end{array}$} & \multicolumn{5}{|c|}{$\begin{array}{c}\text { Níveis de inclusão do farelo integral de mandioca } \\
\text { (Manihot esculenta Crantz), }(\%)\end{array}$} & \multirow[t]{2}{*}{$\mathrm{CV}(\%)$} & \multirow[t]{2}{*}{$\mathrm{P}$} \\
\hline & & 0 & 12 & 24 & 36 & 48 & & \\
\hline \multirow{4}{*}{ GP (g) } & $07-28$ & 715,47 & 622,96 & 649,95 & 628,62 & 642,22 & 6,7 & 0,022 \\
\hline & $29-56$ & 1363,19 & 1428,47 & 1411,11 & 1571,52 & 1547,91 & 4,9 & 0,041 \\
\hline & $57-84$ & 1088,19 & 1148,61 & 1144,44 & 1106,94 & 1139,00 & 6,0 & 0,872 \\
\hline & $07-84$ & 3166,86 & 3200,04 & 3305,50 & 3307,08 & 3329,03 & 3,0 & 0,040 \\
\hline \multirow{4}{*}{$\mathrm{CR}(\mathrm{g})$} & $07-28$ & 1244,86 & 1055,06 & 1122,90 & 1220,83 & 1133,33 & 7,1 & 0,634 \\
\hline & $29-56$ & 3021,52 & 3170,83 & 3172,66 & 3480,55 & 3470,83 & 3,3 & 0,023 \\
\hline & $57-84$ & 3383,47 & 3578,75 & 3774,02 & 3969,30 & 4164,38 & 5,6 & 0,020 \\
\hline & $07-84$ & 7571,58 & 7882,06 & 8192,53 & 8503,00 & 8813,47 & 3,4 & 0,038 \\
\hline \multirow{4}{*}{$\begin{array}{l}\mathrm{CA} \\
(\mathrm{g} / \mathrm{g})\end{array}$} & $07-28$ & 1,74 & 1,69 & 1,75 & 1,94 & 1,77 & 10 & 0,256 \\
\hline & $29-56$ & 2,22 & 2,23 & 2,25 & 2,22 & 2,24 & 5,1 & 0,834 \\
\hline & $57-84$ & 3,04 & 3,24 & 3,09 & 3,63 & 3,88 & 7,5 & 0,028 \\
\hline & $07-84$ & 2,39 & 2,44 & 2,48 & 2,59 & 2,69 & 3,8 & 0,032 \\
\hline
\end{tabular}

Médias seguidas de mesma letra na linha não diferem entre si estatisticamente $(\mathrm{P}>0,05) . \hat{\mathrm{Y}}_{1}=703,43$ $2,44 \mathrm{X}\left(\mathrm{R}^{2}=0,81\right) ; \hat{\mathrm{Y}}_{2}=1363,19+13,96 \mathrm{X}\left(\mathrm{R}^{2}=0,98\right) ; \hat{\mathrm{Y}}_{3}=3175,4+3,595 \mathrm{X}\left(\mathrm{R}^{2}=0,87\right) ; \hat{\mathrm{Y}}_{4}=3.021,52+$ $25,74 \mathrm{X}\left(\mathrm{R}^{2}=0,99\right) ; \hat{\mathrm{Y}}_{5}=3383,47+7,81 \mathrm{X}\left(\mathrm{R}^{2}=0,91\right) ; \hat{\mathrm{Y}}_{6}=7571,58+12,42 \mathrm{X}\left(\mathrm{R}^{2}=0,98\right) ; \hat{\mathrm{Y}}_{7}=3,03+$ $0,006 \mathrm{X},\left(\mathrm{R}^{2}=0,92\right) ; \hat{\mathrm{Y}}_{8}=2,39+0,002 \mathrm{X}\left(\mathrm{R}^{2}=0,92\right)$.

$* \mathrm{CV}=$ coeficiente de variação. 
Rev. Bras. Saúde Prod. Anim., Salvador, v.16, n.1, p.106-117 jan./mar., 2015 http://www.rbspa.ufba.br ISSN 15199940

$\mathrm{Na}$ fase inicial verificou-se efeito linear decrescente de $2,44 \mathrm{~g}$ no ganho de peso para cada $1 \%$ de inclusão do farelo integral de mandioca (FIM), estimado pela equação $\hat{\mathrm{Y}}_{1}=703,43-2,44 \mathrm{X}\left(\mathrm{R}^{2}=\right.$ $0,81)$.

Nas fases crescimento (29-56 dias) observou-se efeito linear crescente para ganho de peso, estimado pela equação $\hat{\mathrm{Y}}_{2}=1363,19+13,96 \mathrm{X}\left(\mathrm{R}^{2}=0,98\right)$, indicando um ganho médio de 13,96g nas aves para cada $1 \%$ de inclusão do FIM. Esse aumento no peso ocorreu, provavelmente, em função do maior consumo de alimento, concomitantemente com o amadurecimento fisiológico do sistema digestivo das aves, o que infere na melhora do crescimento alométrico do aparelho digestório. Estes resultados confirmam os obtidos por Leeson \& Zubair (2004) que, comparando frangos jovens com aves de idade avançada, verificaram maior digestibilidade destes últimos devido ao desenvolvimento biométrico intestinal, aumentando a área absortiva, e à crescente capacidade digestiva dos nutrientes dietéticos.

Já na fase final de produção não foi observado efeito significativo para 0 ganho de peso. Entretanto, no período total (8-84 dias) o ganho de peso apresentou efeito linear crescente com aumento de 3,6 gramas para cada $1 \%$ de inclusão do farelo integral de mandioca, estimado pela equação $\hat{\mathrm{Y}}_{3}=3175,4+$ $3,595 X\left(R^{2}=0,87\right)$.

A perda de peso durante a fase inicial pode ter sido provocada pelo prejuízo no processo de digestão e absorção dos nutrientes em função da quantidade de polissacarídeos não amiláceos, contido no farelo integral de mandioca das rações experimentais, e da imaturidade do trato digestório das aves em digerir tais compostos. Noy \& Sklan (1995) relataram que a ingestão de nutrientes estimula o desenvolvimento do trato gastrintestinal da ave, porém a síntese limitada de enzimas pancreáticas durante os primeiros dias após a eclosão pode limitar o desenvolvimento do animal.

No entanto, com o aumento da idade das aves, possivelmente, ocorreu melhora na maturidade do trato digestivo com possível aumento de secreções enzimáticas e da população de bactérias simbióticas que colonizam o trato digestivo das aves capazes de fermentar parte dos conteúdos fibrosos da dieta.

Observou-se, ainda, que o ganho de peso das aves nas fases de crescimento e final foi capaz de suplantar as perdas ocorridas durante a fase inicial evidenciando um ganho de peso compensatório, influenciado principalmente pelo aumento do consumo de ração nestas fases.

Para consumo de ração, na fase inicial não foi observado efeito significativo, indicando que a inclusão do farelo integral de mandioca nas dietas não teve influência sobre este parâmetro. Nas fases de crescimento (29-56 dias) e final (57 a 84 dias) observou-se efeito linear crescente, com aumento no consumo de ração de $25,74 \mathrm{~g}$ e de $7,81 \mathrm{~g}$, respectivamente, para cada $1 \%$ de inclusão do farelo integral de mandioca, estimado pelas equações $\hat{\mathrm{Y}}_{4}=3.021,52$ $+25,74 \mathrm{X}\left(\mathrm{R}^{2}=0,99\right)$ para crescimento e $\hat{Y}_{5}=3383,47+7,81 X\left(R^{2}=0,91\right)$ para a fase final.

No período total (8-84 dias) observouse igualmente efeito linear crescente $\left(\hat{\mathrm{Y}}_{6}=7571,58+12,42 \mathrm{X}, \mathrm{R}^{2}=0,98\right)$, indicando um aumento médio no consumo de ração durante todo período de criação de 12,42 g para cada $1 \%$ de inclusão do farelo integral de mandioca nas dietas.

O aumento no consumo de ração a partir dos 28 dias de idade provavelmente ocorreu em função das aves terem buscado atender seus 
Rev. Bras. Saúde Prod. Anim., Salvador, v.16, n.1, p.106-117 jan./mar., 2015 http://www.rbspa.ufba.br ISSN 15199940

requerimentos de energia, pois, como descrito por Nascimento et al. (2005) o farelo de mandioca apresenta polissacarídeos não amiláceos (fatores anti-nutricionais) que provocam menor eficiência no aproveitamento da dieta, proporcionando menor ganho diário de peso e diminuição na digestibilidade de diversos nutrientes da dieta.

Para a variável conversão alimentar não se verificou efeito significativo da inclusão do farelo integral de mandioca nas fases inicial e de crescimento, no entanto, na fase final (57-84 dias) observou-se efeito linear crescente com aumento na taxa de conversão alimentar de 6 pontos para cada $1 \%$ de inclusão do farelo de mandioca estimado pela equação $\hat{\mathrm{Y}}_{7}=3,03+0,006 \mathrm{X},\left(\mathrm{R}^{2}=\right.$ $0,92)$.

No período total (8-84 dias) também se observou efeito linear crescente na taxa de conversão alimentar, com aumento de dois pontos para cada ponto percentual de inclusão de farelo integral de mandioca, estimado pela equação $\hat{\mathrm{Y}}_{8}$ $=2,39+0,002 X\left(\mathrm{R}^{2}=0,92\right)$.

Resultados semelhantes foram observados por Nascimento et al. (2005), Costa et al. (2009) e Oladunjoye et al. (2010) com poedeiras comerciais. Esses últimos autores também observaram aumento da conversão alimentar nos tratamentos que continham níveis de inclusão elevados de farelo integral de mandioca nas dietas.

Na Tabela 6 observam-se os resultados obtidos da avaliação da carcaça e de suas partes, em termos percentuais, em função dos níveis de inclusão do farelo integral de mandioca.

A análise de regressão para rendimento percentual da carcaça demonstra que para asas, dorso, peito e coxas não houve efeito significativo. Resultados semelhantes de avaliação de carcaças de frangos de corte caipiras foram obtidos por Santos et al. (2005) e Takahashi et al. (2006).

Tabela 6. Rendimento percentual dos cortes comerciais e vísceras das carcaças de frangos caipiras em função dos níveis de inclusão do farelo integral de mandioca (FIM)

\begin{tabular}{|c|c|c|c|c|c|c|c|}
\hline \multirow[t]{2}{*}{ Variável (\%) } & \multicolumn{5}{|c|}{$\begin{array}{l}\text { Níveis de inclusão do farelo integral de mandioca } \\
\text { (Manihot esculenta Crantz), }(\%)\end{array}$} & \multirow[t]{2}{*}{$\mathrm{CV}(\%)$} & \multirow[t]{2}{*}{$\mathrm{P}$} \\
\hline & 0 & 12 & 24 & 36 & 48 & & \\
\hline Carcaça & 88,33 & 89,20 & 88,67 & 88,68 & 88,31 & 5,2 & 0,536 \\
\hline Asa & 10,40 & 9,85 & 9,77 & 10,07 & 10,28 & 5,1 & 0,465 \\
\hline Dorso & 18,85 & 19,77 & 18,49 & 19,66 & 18,04 & 9,3 & 0,562 \\
\hline Peito & 25,46 & 25,55 & 24,97 & 24,19 & 24,71 & 9,0 & 0,851 \\
\hline Coxa & 13,78 & 13,30 & 13,18 & 13,21 & 14,16 & 7,3 & 0,782 \\
\hline Sobrecoxa & 15,70 & 15,92 & 16,21 & 16,15 & 17,18 & 6,0 & 0,031 \\
\hline Gordura abdominal & 4,76 & 4,65 & 5,11 & 5,20 & 5,50 & 13,0 & 0,034 \\
\hline Fígado & 1,92 & 1,89 & 2,08 & 2,11 & 2,29 & 13,0 & 0,028 \\
\hline Coração & 0,57 & 0,50 & 0,64 & 0,60 & 0,60 & 14,0 & 0,520 \\
\hline Moela & 3,60 & 3,34 & 3,52 & 3,54 & 3,46 & 18,0 & 0,862 \\
\hline
\end{tabular}

${ }^{*} \mathrm{CV}=$ coeficiente de variação. Médias seguidas de mesma letra na linha não diferem entre si estatisticamente $(\mathrm{P}>0,05), \hat{\mathrm{Y}}_{9}=15,59+0,013 \mathrm{X}\left(\mathrm{R}^{2}=0,79\right) ; \hat{\mathrm{Y}}_{10}=1,86+0,004 \mathrm{X}\left(\mathrm{R}^{2}=0,88\right)$ e $\hat{\mathrm{Y}}_{11}=4,65+$ $0,013 X\left(R^{2}=0,87\right)$. 
Rev. Bras. Saúde Prod. Anim., Salvador, v.16, n.1, p.106-117 jan./mar., 2015 http://www.rbspa.ufba.br ISSN 15199940

Para sobrecoxas verificou-se aumento linear de $0,013 \%$ para cada $1 \%$ de inclusão de farelo de mandioca determinado pela equação $\hat{\mathrm{Y}}_{9}=15,59+$ $0,013 \mathrm{X}\left(\mathrm{R}^{2}=0,79\right)$. $\mathrm{O}$ aumento no percentual do peso das sobrecoxas observado neste experimento demonstra que a partir do momento em que o organismo atingiu a maturidade em síntese e deposição proteica, o ganho em músculo passa a ser mais distribuído em todo corpo do animal, deixando de depositar prioritariamente para crescimento da musculatura do peito, passando então a haver deposição na musculatura do sistema locomotor, pois existe a necessidade de reforçar a referida musculatura para facilitar a locomoção das aves em função do aumento do peso corporal sobre $\mathrm{o}$ esqueleto.

Semelhantemente observou-se aumento linear de $0,004 \%$ para rendimento de fígado e de $0,008 \%$ para deposição de gordura abdominal para cada $1 \%$ de inclusão do farelo integral de mandioca determinados pelas equações $\hat{Y}_{10}=1,86$ $+0,004 \mathrm{X}\left(\mathrm{R}^{2}=0,88\right)$ e $\hat{\mathrm{Y}}_{11}=4,65+$ $0,013 \mathrm{X}\left(\mathrm{R}^{2}=0,87\right)$ respectivamente, indicando um possível aumento da taxa metabólica, em função da maior disponibilidade de carboidratos metabolizados para serem armazenados no organismo na forma de gordura abdominal. Bertechini (2006) descreveu que a maior parte dos carboidratos metabolizados são armazenados na forma de gordura, o que representa a reserva energética do animal.

Quando as aves atingiram o máximo de deposição proteica e crescimento muscular, possivelmente o excesso de nutrientes foi metabolizado para deposição de gordura na carcaça, passando o crescimento orgânico a ocorrer de forma mais lenta, com isso o consumo de proteína da dieta continuou constante, submetendo o organismo da ave a elevado custo metabólico para excreção do excesso de nitrogênio consumido. Esse prejuízo é relatado por Costa et al. (2001), ao afirmarem que o gasto energético para incorporar um aminoácido na cadeia proteica estimado em 4 mol de trifosfato de adenosina (ATP) e o custo para excretar um aminoácido é estimado em torno de seis e 18 moles de ATP, podendo variar de acordo com a quantidade de nitrogênio presente no aminoácido.

Carrijo et al. (2010) avaliando níveis de inclusão de até $45 \%$ de farelo de raspa integral de mandioca em dietas de frangos de corte fêmeas da linhagem Label Rouge também não observaram significância para as variáveis de desempenho $\mathrm{e}$ características de carcaça.

$\mathrm{O}$ uso de ingredientes alternativos ao milho e ao farelo de soja em rações para aves, geralmente causa desconfiança ao produtor rural mesmo quando os resultados do ponto de vista zootécnico são satisfatórios, principalmente àqueles que usam frequentemente milho e farelo de soja até em épocas de escassez de produto provocando aumento nos preços e, consequentemente, no custo de produção.

Conclui-se que o farelo integral de mandioca pode ser incluído em até $48 \%$ nas rações para frangos caipiras, sem prejuízo ao desempenho zootécnico das aves.

\section{AGRADECIMENTOS}

À Fundação de Amparo à Ciência e Tecnologia do Estado de Pernambuco - FACEPE por ter fomentado esta pesquisa e, as empresas Avícola Ferraz Ltda, Poli-nutri Alimentos Ltda, e Uniaves Ltda, pelo fornecimento das matérias primas utilizadas nesta pesquisa. 
Rev. Bras. Saúde Prod. Anim., Salvador, v.16, n.1, p.106-117 jan./mar., 2015 http://www.rbspa.ufba.br ISSN 15199940

\section{REFERÊNCIAS}

ASSOCIATION OF OFFICIAL ANALYTICAL CHEMISTRY AOAC. Official methods of analysis. 16.ed. Arlington, 1995, 1025p.

BERTECHINI, A.G. Nutrição de Monogástricos. Lavras, MG:

Universidade Federal de Lavras, 2006. 303p.

CARRIJO, A.S.; FASCINA, V.B.; SOUZA, K.M.R.;RIBEIRO, S.S.; ALLAMAN, I.B.; GARCIA, A.M.L.; HIGA, J.A. Níveis de farelo da raiz integral de mandioca em dietas para fêmeas de frangos caipiras. Revista Brasileira de Saúde e Produção Animal [online], v.11, n.1, p.131-139, 2010.

CHAUYNARONG, N.; ELANGOVAN A.V.; IJI P.A. The potential of cassava products in diets for poultry. World's Poutry Science Journal, v.65, p.23-36, 2009.

COSTA, F.G.P.; ROSTAGNO, H.S.; ALBINO, L.F.T.; GOMES, P.C.; TOLEDO , R.S.; VARGAS JUNIOR, J.G. Níveis dietéticos de proteína bruta para frangos de corte de 1 a 21 e 22 a 42 dias de idade. Revista Brasileira de Zootecnia, v.30, n.5, p.1498-1505, 2001.

COSTA, F.G.P.; GOULART, C.C.; COSTA, J.S.; SOUZA, C.J.; BARROS, L.R.; SILVA, J.H.V. Desempenho, qualidade de ovos e análise econômica da produção de poedeiras semipesadas alimentadas com diferentes níveis de raspa de mandioca. Acta Scientiarum. Animal Science, v.31, n.1, p.13-18, 2009.
FREITAS, C.R.G.; LUDKE, M.C. M.M.; LUDKE, J. V.; RABELLO, C. B.V.; NASCIMENTO, G. R.; BARBOSA, E. N. R. Inclusão da farinha de varredura de mandioca em rações de frangos de corte. Acta Scientiarum. Animal Sciences, v. 30, n. 2, p. 155-163, 2008.

\section{LEESON, S.; ZUBAIR, A.K. Digestion} in poultry: proteins, fats and starch. Department of Animal and Poultry Science, University of Guelph. Guelph, Ontario, Canadá, 2004. Disponível em: <http://www.novusint.com/Public/Libra ry/DocViewer.asp>. Acesso em: 28 jul. 2013.

LUDKE, J.V.; BERTOL, T.M.; MAZZUCO, H.; LUDKE, M.C.M.M. Uso racional da mandioca e subprodutos na alimentação de aves e suínos. In: SOUZA, L.S.; FARIAS, A.R.N.; MATTOS, P.L.P. et al. Processamento e utilização da mandioca. Brasília: Embrapa Informação Tecnológica, 2005. p.299443.

MENDONÇA, M.O.; SAKOMURA, N.K.; SANTOS, F.R.; BARBOSA, N. A.A.; FERNANDES, J.B.K.; FREITAS, E.R. Níveis de energia metabolizável e relações energia:proteína para aves de corte de crescimento lento criadas em sistema semiconfinado Acta Scientiarum. Animal Science, v.29, n.1, p.23-30, 2007.

NASCIMENTO, G.A.J.; COSTA, F.G.P.; JÚNIOR, V.S.A.; BARROS, L.R. Efeitos da substituição do milho pela raspa de mandioca na alimentação de frangos de corte, durante as fases de engorda e final. Ciência Agrotécnica, v.29, n.1, p.200-207, 2005. 
Rev. Bras. Saúde Prod. Anim., Salvador, v.16, n.1, p.106-117 jan./mar., 2015 http://www.rbspa.ufba.br ISSN 15199940

NASCIMENTO, D.C.N.;

SAKOMURA, N.K.; SIQUEIRA, J.C.; PINHEIRO, S. R.F.;

FERNANDES;J.B.K.; FURLAN, R.L.

Exigências de metionina+cistina

digestível para aves de corte ISA Label criadas em semiconfinamento. Revista

Brasileira de Zootecnia, v.38, n.5, p.869-878, 2009.

NASCIMENTO, D.C.N.;

SAKOMURA, N.K.; SIQUEIRA, J.C.; DOURADO, L.R.B.; FERNANDES, J.B.K.; MALHEIROS, E.B. Exigências de lisina digestível para aves de corte da linhagem ISA Label criadas em semiconfinamento. Arquivo Brasileiro de Medicina Veterinária e Zootecnia, v.61, n.5, p.1128-1138, 2009.

NOY, Y.; SKLAN, D. Digestion and absorption in the young chicks. Poultry Science, v.74, n.2, p.366-373, 1995.

OLADUNJOYE I, O.; OJEBIYI, O.; AMAO, O.A. Effect of feeding processed cassava (Manihot esculenta crantz) peel meal based diet on the performance characteristics, egg quality and blood profile of laying chicken.

Agricultura Tropica et Subtropica, v.43, n.2, p.119-126, 2010.

SANTOS, A.L.; SAKOMURA, N.K.; FREITAS, E.R.; FORTES, C.M.S; CARRILHO, E.N.V.M. Comparison of free range broiler chicken strains raised in confined or semi-confined systems. Brazilian Journal of Poultry Science, v.7, n.2, p.85-92, 2005.

STATISTICS ANALYSIS SYSTEM.

SAS: user's guide: statistics: version 8 . Cary: SAS Institute inc, 2001.
TAKAHASHI, S.E.; MENDES, A.A.;

SALDANHA, E.S.P.B.;

PIZZOLANTE, C.C.; PELÍCIA, K.;

GARCIA, R.G.; PAZ, I.C.L.A.;

QUINTEIRO, R.R.. Efeito do sistema

de criação sobre o desempenho e rendimento de carcaça de frangos de corte tipo colonial. Arquivo Brasileiro de Medicina Veterinária e Zootecnia, v.58, n.4, p.624-632, 2006.

Data de recebimento: 19/03/2014

Data de aprovação: 16/02/2014 